\title{
Unilateral Pulmonary Aplasia: A Case Report
}

\author{
Shrestha $\mathrm{P}^{1}$, Poudel $\mathrm{P}^{2}$, Shah $\mathrm{PL}^{3}$ \\ ${ }^{1}$ Dr. Prabina Shrestha, MBBS, Junior Resident, ${ }^{2}$ Dr. Prakash Poudel, MBBS. MD. Assistant Professor, Department \\ of Paediatrics and Adolescent Medicine, ${ }^{3} \mathrm{Dr}$. Panna Lal Sah, MBBS, MD. Assistant Professor, Department of \\ Radiodiagnosis. All from BP Koirala Institute of Health Sciences, Dharan, Nepal.
}

Adress for Correspondence: Dr. Prakash Poudel, E-mail: prakashpdl@hotmail.com

\begin{abstract}
Chest X-Ray findings of unilateral lung or lobar collapse with a shift of mediastinal shift towards the affected side may prompt differential diagnoses of suspected foreign body aspiration, mucus plug occlusion, and bronchial mass lesions. We must also consider the rare condition of pulmonary agenesis. It is one of the rare congenital abnormalities in the development of the lungs in which there is complete absence of a lung. We report a three month old child with right sided pulmonary aplasia.
\end{abstract}

Key words: Agenesis lung, pulmonary aplasia, congenital abnormality

\section{Introduction}

$\mathrm{P}$ ulmonary agenesis, aplasia and hypoplasia are few congenital abnormalities of the lung which are rare. Pulmonary agenesis is the complete absence of the lung parenchyma, its vasculature, and its bronchus ${ }^{1}$. Pulmonary aplasia, the most common variant, consists of a carina and the main-stem bronchial stump with absence of the distal lung ${ }^{2}$. Presentation is with usual respiratory symptoms like noisy breathing, fast breathing, repeated respiratory tract infections and respiratory distress ${ }^{2}$. We present a case report of a three month old boy with unilateral pulmonary aplasia of right lung found incidentally during out patient visit for noisy breathing.

\section{Case Report}

A three month old boy from Dharan, presented to Paediatric out patient clinic of BP Koirala Institute of Health Sciences with complaints of fever and noisy breathing for two days. There was no history of chocking during feeding, foreign body inhalation, cough, vomiting, suckpause-suck cycle, cyanosis, swelling of body and similar illness in the past. He was born to a $36 \mathrm{yr}$ old second gravida mother with non consanguineous marriage at term gestation with no perinatal complications. Developmental milestones were normal for age.

On examination, he was active, alert with normal

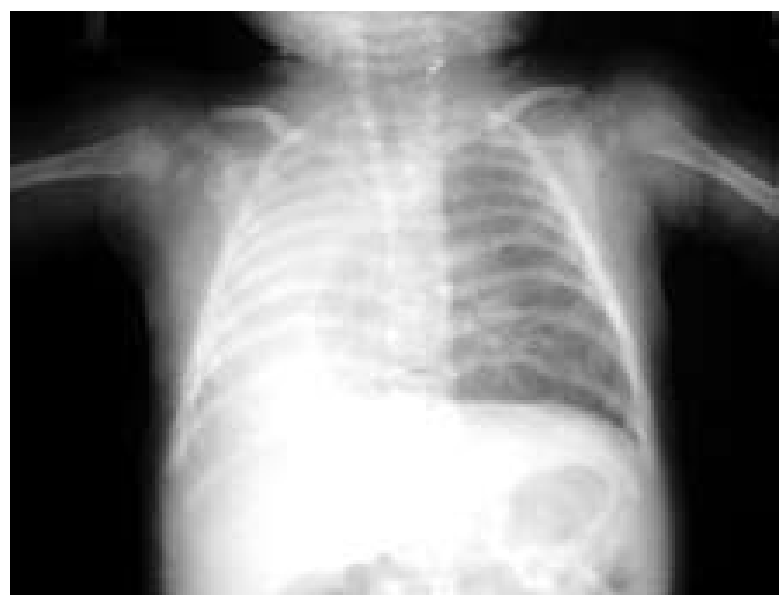

Fig 1: Chest $X$ Ray showing right sided pulmonary aplasia with hypertrophy of left lung.

anthropometry. He had tachycardia (heart rate-120/min), tachypnea (respiratory rate-64/min) with mild subcostal recession. His chest was normal shaped, with slightly decreased movements on right side. Trachea was slightly deviated towards right side. Apex beat was palpable on right side at $5^{\text {th }}$ intercostal space in anterior axillary line. There was dull percussion note on the whole of the right side of chest; and there was no cardiac dullness on the left side. Breath sounds were reduced on the right side. On abdominal examination, liver was palpated on right side, one $\mathrm{cm}$ below costal margin. 


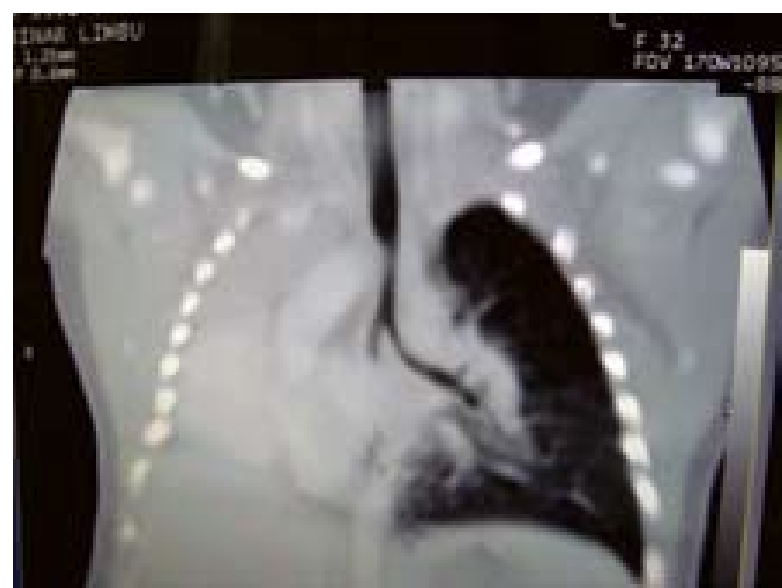

Fig 2: CT Chest (coronal section) showing absence of lung, pulmonary artery and veins on right side.

Chest $X$ ray (Fig. 1) showed complete opacification of the right hemithorax with mediastinal shift towards right. Lung on left side was hypertrophied with gross herniation to the right. CT Chest (Fig. 2 \& 3) showed complete opacification of right hemithorax with ipsilateral absence of pulmonary artery and vein. There was shift of mediastinum towards right side with tenting of right diaphragm and over-distension of contra lateral lung. There is abrupt cut-off of distal right main-stem bronchus.

Diagnosis of right pulmonary aplasia was made. Patient was given antibiotics for seven days. He was afebrile and respiratory symptoms improved, after four days.

\section{Discussion}

Many cases of pulmonary agenesis, aplasia and hypoplasia have been reported at different agesprenatally in newborns, infants, children and adults, even at 90 years of age $\mathrm{e}^{1,3-5}$. Bilateral pulmonary agenesis is a rare malformation that may occur in anencephalic babies ${ }^{2}$. Slightly more common are unilateral agenesis, aplasia and hypoplasia which may have few symptoms and non-specific findings, among which only one-third are diagnosed during life ${ }^{6}$. Functionally, unilateral agenesis and aplasia are similar. The sole lung is larger than normal and this enlargement is true hypertrophy and not emphysema ${ }^{2}$.

Embryologically, these malformations correspond to a failure of development of the respiratory system from the foregut. Arrest at the stage of the primitive lung bud produces bilateral pulmonary agenesis. The respiratory anlage at a later stage may develop only unilaterally and lead to lung agenesis. Lobar agenesis results when developmental arrest on one side occurs

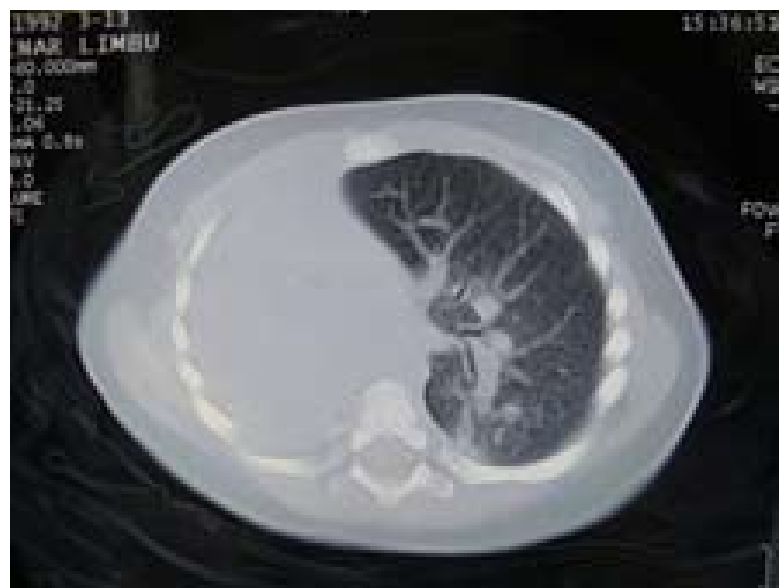

Fig 3: CT Chest (transverse section) showing absence of lung, pulmonary artery and veins on right side suggestive of right sided unilateral pulmonary aplasia.

in an older embryo. Pulmonary hypoplasia may occur during the last trimester of pregnancy with failure of final alveolar differentiation². Pulmonary agenesis and aplasia are rare abnormalities thought to have an incidence between $0.0034 \%$ and $0.0097 \% .^{7}$ Genetic, teratogenic and mechanical factors may have a bearing on etiology. ${ }^{3,6}$ They are generally sporadic, with only a few reports of these conditions occurring in siblings in an autosomal recessive pattern. ${ }^{1}$ They occur with equal frequency in both sexes and involve both lungs equally. ${ }^{1,3}$ There is high incidence ( $>50.0 \%$ ) of associated cardiac, gastrointestinal, genitourinary, skeletal, central nervous system malformations and VACTERL sequence ${ }^{2,3,6,8}$.

Diagnosis should be suspected when respiratory difficulty occurs with tracheal deviation, in the presence of a clinically symmetric chest and Chest $X$-ray suggestive of massive atelectasis with mediastinal shift ${ }^{2}$.

No treatment is required in asymptomatic cases ${ }^{2}$. Treatment is necessary for lower respiratory tract infections. Patients having stumps may require surgical removal of the stump if postural drainage and antibiotics fail to resolve the infection ${ }^{9}$. Corrective surgery of associated congenital anomalies, wherever feasible, may be undertaken ${ }^{10}$.

Prognosis depends on two factors. Firstly, the severity of associated congenital anomalies and secondly, involvement of the normal lung in any disease process ${ }^{10}$. Patients with right lung agenesis have a higher mortality than those with left lung agenesis because of compression of the tracheobronchial tree by the shifting of normally midthoracic structures into the right chest ${ }^{3}$. If patient survives the first five years without major infection, an almost normal life span can be expected ${ }^{11}$. 


\section{References}

1. Lee P, Westra S, Baba T, McCauley R. Pediatr Radiol 2006;36:449-52.

2. Krummel TM. Congenital malformations in the lower respiratory tract. In: Chernick V, Boat $T F$, Kendig E L editors. Kendig's Disorders of The Respiratory Tract in Children. $6^{\text {th }}$ Ed. Philadelphia: WB Saunders Company; 1998. p. 307-8.

3. Maltz D L, Nadas A S. Agenesis of the lung : presentation of 8 new cases and review of literature. Pediatrics 1968;2:175-88.

4. Holstein A, Weber M. An extraordinary finding - accidental diagnosis of complete pulmonary aplasia in a 90 yr old lady. Age and Aging 2009;38: 487

5. Gabarre JA, IzquierdoAG, Ponferrada MR, Gallardo CO, Agueda JMP, Perez PF. Isolateral unilateral pulmonary agenesis: early prenatal diagnosis and long term follow up. J Ultrasound Med 2005;24: 865-8.
6. Finda JD, Michelson PH. Congenital disorders of the lung. In: Behrman RE, Kliegman RM, Jenson HB editors. Nelson Textbook of Pediatrics. $18^{\text {th }}$ Ed. Philadelphia: Saunders; 2008. p. 1783.

7. Mardini M K, Nyhan W L. Agenesis of lung: Report of 4 patients with unusual anomalies. Chest 1983; 87:522-7.

8. Fitoz S, Ucar T, Erden A, Gunlemez A. DiGeorge syndrome associated with left lung aplasia. $\mathrm{Br} \mathrm{J}$ Radiol 2001;74:764-6.

9. Rajshekhar B, Gomber S, Krishna A. Pulmonary agenesis. Indian Pediatr 1997;34:534-8.

10. Chopra K, Sethi GR, Kumar A, Kapoor R, Saha MM, Mital M, Saluja S. Pulmonary agenesis. Indian Pediatr 1988;25:678-82.

11. Spokos CG, Mc Millan IKR. Agenesis of lung. $\mathrm{Br} \mathrm{J}$ Dis Chest 1977;71:183-97. 